\title{
Utilização de técnica rápida de aglutinação em látex para determinação semiquantitativa dos níveis séricos de proteína C reativa em cães*
}

\author{
Use of a rapid latex agglutination technique to measure C-reactive protein levels in dogs
}

\author{
Angela Patricia Medeiros Veiga ${ }^{1}$, Simone Tostes de Oliveira ${ }^{1}$, Vanessa Esteves ${ }^{1}$, \\ Valério Marques Portela ${ }^{2}$, Andrea Pires dos Santos ${ }^{1} \&$ Félix Hilario Díaz González ${ }^{1}$
}

\begin{abstract}
RESUMO
A determinação dos níveis de proteína $\mathrm{C}$ reativa vem se tornando uma ferramenta bastante útil na clínica canina para a avaliação de variados tipos de quadros infecciosos e inflamatórios, porém a técnica correntemente utilizada é pouco acessível economicamente e comercialmente indisponível no Brasil. O presente estudo teve como objetivos testar uma técnica acessível e de fácil realização para a determinação clínica dos níveis séricos de proteína $\mathrm{C}$ reativa em cães. O soro originário de coleta sanguínea venosa de trinta cães em jejum de 12 horas, machos e fêmeas, clinicamente sadios, separados em grupo controle $(n=15)$ e grupo obeso $(n=15)$ foi submetido simultaneamente às duas técnicas para determinação dos níveis de proteína C reativa, considerando-se a de uso corrente (ELISA) o gold standard. A partir da aplicação de análise de variância (ANOVA) não paramétrica e teste de Wilcoxon, valores mais baixos de proteína $\mathrm{C}$ reativa foram observados para o grupo obeso, tanto através de ELISA ( $p<0,001)$ quanto de aglutinação em látex ( $p<0,01)$. Além disso, as técnicas mostraram uma correlação positiva significativa entre si $\left(\mathrm{p}<0,001 ; \mathrm{R}^{2}=0,62\right)$. A aglutinação em látex mostrou ser um teste eficaz e clinicamente útil para a determinação semiquantitativa dos níveis de proteína $\mathrm{C}$ reativa na espécie canina.
\end{abstract}

Descritores: inflamação, obesidade, sistema imune, anticorpos.

\section{ABSTRACT}

The measurement of C-reactive protein levels is becoming a useful tool in canine clinics to evaluate a number of infectious and inflammatory diseases, however the technique currently used is expensive and unavailable in Brazil. The present study had the aim of testing a low-cost and easy-performing technique for clinical determination of C-reactive protein serum levels in dogs. Thus, the serum originate from venous blood collection of thirty, 12-fastened, male and female, healthy $\operatorname{dog}$, shared in control group $(n=15)$ and obese group $(n=15)$ was submitted simultaneously to both techniques to determine $\mathrm{C}$-reactive protein serum levels, considering the currently used (ELISA) the gold standard technique. Lower levels of Creactive protein were observed in obese group, through as ELISA $(p<0.001)$ as latex agglutination as compared by nonparametric ANOVA and Wilcoxon test $(\mathrm{p}<0.01)$. Additionally, the techniques showed a significant positive correlation between each other $\left(p<0.001 ; R^{2}=0.62\right)$. Latex agglutination showed to be an efficacious and clinically useful test to semi-quantitative measurement of $\mathrm{C}$-reactive protein levels in canine species.

Keywords: inflammation, obesity, immune system, antibodies.

*Trabalho originado da Tese do primeiro autor [Programa de Pós-Graduação em Ciências Veterinárias (PPGCV), Universidade Federal do Rio Grande do Sul (UFRGS), 91540-00, Porto Alegre, RS, Brasil]. ${ }^{1}$ Universidade Federal do Rio Grande do Sul (UFRGS). ${ }^{2}$ Université de Montréal (UdeM), Montréal, Canadá. CORRESPONDÊNCIA: A.Veiga [angela.pmv@ gmail.com]; FAX: +55 (51) 33087305. 


\section{INTRODUÇÃO}

A proteína $\mathrm{C}$ reativa $(\mathrm{PCR})$ consiste em uma proteína de fase aguda produzida pelo fígado e tecido adiposo sob estímulo de mediadores pró-inflamatórios, dentre os quais citam-se fator de necrose tumoral (TNF-•) e interleucinas (IL) 1 e 6, seus aumentos séricos estando relacionados a quaisquer eventos que levem à injúria tecidual $[1,8]$, com a função de opsonização e ativação do complemento. Devido ao seu caráter agudo, tais elevações ocorrem antes das demais manifestações clínico-laboratoriais inflamatórias e infecciosas, como febre, neutrofilia e monocitose [9], sendo também importante no acompanhamento do restabelecimento clínico do animal, quando ocorre a queda dos níveis séricos de PCR. O canino não responde tão bem com aumento de fibrinogênio nos quadros inflamatórios agudos [13] como equinos e bovinos. Portanto, a mensuração sérica de proteína $\mathrm{C}$ reativa se mostra eficaz na avaliação inflamatória principalmente na mencionada espécie, em detrimento de outras provas.

A técnica considerada gold standard para esta avaliação, enzyme-linked immunosorbant assay (ELISA), apesar de específica para a espécie em questão, já que emprega microplacas revestidas com anticorpos contra CRP canina, é bastante dispendiosa, pois requer o uso de equipamentos e materiais inexistentes no mercado nacional, sendo utilizada mais em pesquisas do que clinicamente.

O presente estudo tem por objetivo comparar o emprego da técnica de aglutinação rápida em látex, através de um kit humano disponível no mercado nacional com a técnica de ELISA, já estabelecida para a quantificação de proteína $\mathrm{C}$ reativa canina.

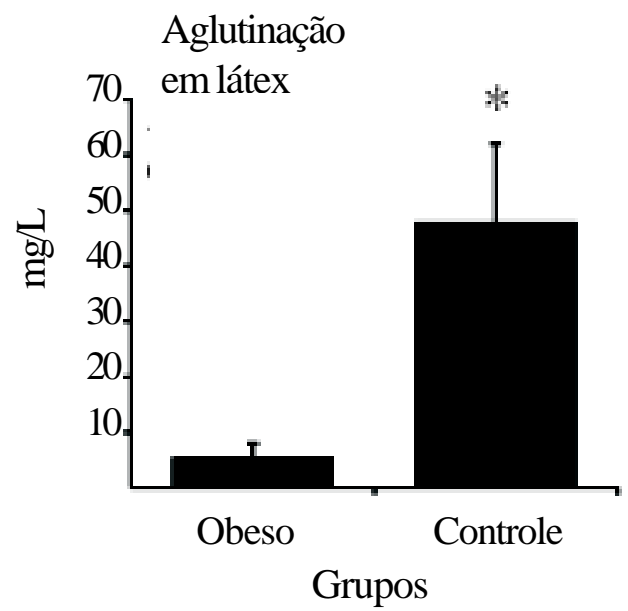

\section{MATERIAIS E MÉTODOS}

Trinta cães, machos e fêmeas, sadios, de diferentes raças, foram usados neste estudo. Previamente ao experimento, sua saúde geral foi avaliada através de exames clínico-laboratoriais. Os animais foram pesados e seu escore de condição corporal (ECS) conforme a escala de 9 pontos, foi determinado [5,6]. Quinze cães cujos ECS permaneceram entre 3 e 5 foram enquadrados no grupo controle, enquanto os outros 15 , cujos ECS permaneceram entre 7 e 9 foram enquadrados no grupo obeso. O sangue venoso foi coletado após jejum de 12 horas e o soro foi imediatamente separado e armazenado para posterior determinação simultânea dos níveis séricos de PCR por ELISA ${ }^{1}$ e aglutinação em látex ${ }^{2}$. Os ensaios foram realizados com kits comerciais, de acordo com as instruções dos fabricantes. Para a técnica de ELISA, cada amostra teste, assim como as amostras da curva padrão, foram dosadas em duplicata. Após a incubação recomendada, a leitura das microplacas foi realizada em equipamento leitor de $\mathrm{ELISA}^{3}$, em laboratório próximo. Para a técnica de aglutinação em látex, os soros foram diluídos seriadamente, até que a aglutinação não fosse mais evidenciada visualmente, comparando-se com o controle positivo, e o resultado em $\mathrm{mg} / \mathrm{L}$ foi obtido multiplicando-se o fator da última diluição, cuja aglutinação ocorreu, por 6 , conforme instruções do fornecedor.

Todos os princípios éticos recomendados quanto à utilização de animais em experimentos foram observados (Colégio Brasileiro de Experimentação Animal).

Para testar o efeito da obesidade sobre os níveis séricos de proteína $\mathrm{C}$ reativa determinada por ambos os testes, foi utilizada ANOVA não paramétrica.

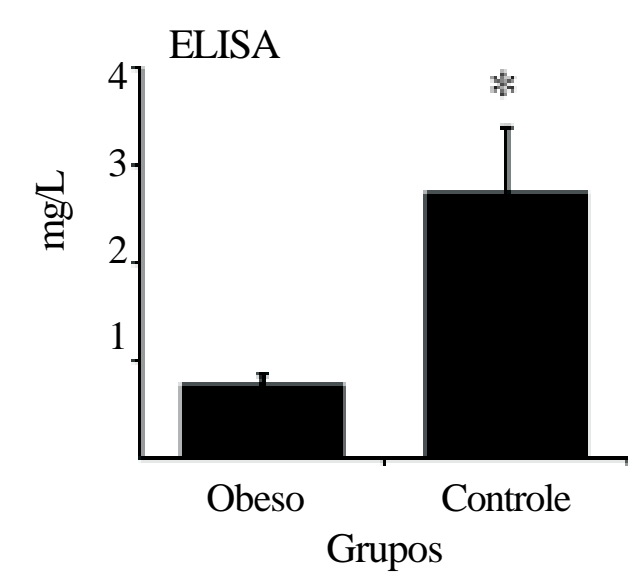

Figura 1. Valores médios e erros-padrão de proteína $\mathrm{C}$ reativa entre grupos obeso e controle, determinados por aglutinação em látex $(\mathrm{p}=0,0013)$ e ELISA $(\mathrm{p}=0,0004)$. Valores de $\mathrm{p}<0,05$ foram considerados significativos pelo teste de Wilcoxon $(*)$. 
Tabela 1. Valores médios, máximos, mínimos e deviospadrão de proteína $\mathrm{C}$ reativa em $\mathrm{mg} / \mathrm{L}$ de cães, determinados por ELISA ou aglutinação em látex.

\begin{tabular}{ccc}
\hline TESTE & VALOR & N \\
\hline \multirow{2}{*}{ ELISA } & $5,6 \pm 1,98^{\mathrm{b}}$ & 30 \\
& $(0,5-8,8)$ & \\
LÁTEX & $48,0 \pm 27,9^{\mathrm{a}}$ & 30 \\
& $(5-192)$ & \\
\hline
\end{tabular}

Letras sobrescritas diferentes na mesma coluna indicam $\mathrm{p}<0,05$.

As médias foram comparadas pelo teste Wilcoxon. Para comparação dos resultados obtidos pelas técnicas de aglutinação em látex e ELISA, foi realizada uma análise de correlação simples. O nível de significância considerado foi de $95 \%$. As análises foram realizadas utilizando-se o programa estatístico JMP ${ }^{4}$.

\section{RESULTADOS}

Em ambas as técnicas, o grupo de cães obesos apresentou valores mais baixos de PCR do que o grupo controle ( $\mathrm{p}<0,01$; Figura 1), além de ter sido observada uma correlação positiva significativa entre as duas técnicas ( $\mathrm{p}<0,001, \mathrm{r}=0,62$; Figura 2). Os valores encontrados com o emprego da aglutinação em látex foram mais altos do que os encontrados com o emprego de ELISA ( $p<0,05$; Tabela 1$)$.

\section{DISCUSSÃO}

Diversas técnicas já foram empregadas para a determinação dos valores séricos de PCR canina, como ensaio imunoelétrico [2], ELISA [4], ensaio imunotubidimétrico [3] aglutinação em látex capilar reversa passiva [12], cromatografia [7] e imuno-fluorimetria [11].

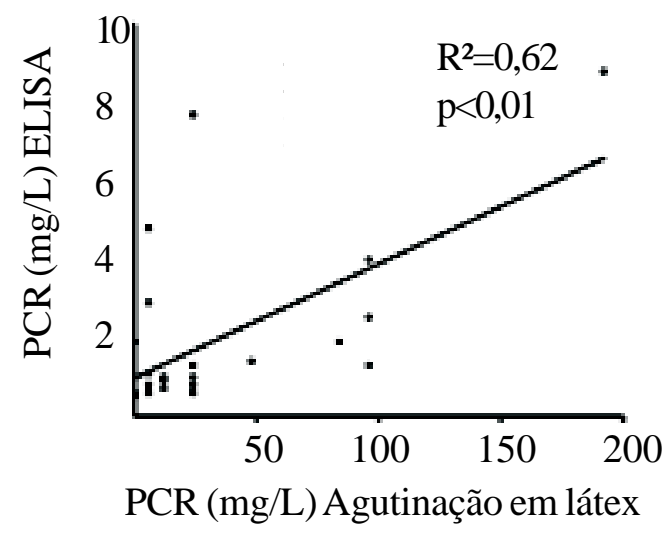

Figura 2. Correlação entre Aglutinação em Látex (eixo x) e ELISA (eixo y) na determinação de proteí-na C-reativa (mg/ L) em 30 amostras de soro canino.
O kit empregado para realização da técnica de aglutinação em látex baseia-se na reação imunológica entre a PCR de amostras de pacientes ou soros controle e seu anticorpo antiPCR humana correspondente ligados a partículas de látex, sendo que a reação positiva é indicada pela nítida aglutinação das partículas de látex (Figura 3).

O fato de as espécies Homo sapiens e Canis lupus familiaris apresentarem $60 \%$ de homologia torna relativamente alta a probabilidade de reações cruzadas entre anticorpo humano e PCR canina. Uma correlação positiva altamente significativa foi observada entre as técnicas utilizadas ( $p<0,001, R^{2}=0,62$; Figura 2). Assim, e pela confirmação dos resultados quando as mesmas amostras foram submetidas ao gold standard (Figura 1), o teste rápido de aglutinação em látex mostrou-se eficaz na determinação dos níveis séricos de PCR canina. Outras provas, como a aglutinação em látex capilar reversa passiva com anticorpos antiPCR canina [12,15], o ensaio fluorimétrico [11] e a imunocromatografia [7] já foram comparadas à ELISA canina, com bons resultados, porém esses kits também não estão comercialmente disponíveis no Brasil.

Os valores de PCR obtidos através da aglutinação em látex foram maiores do que os obtidos através da mensuração por ELISA, os últimos permanecendo dentro dos valores de referência para a espécie [4,11]. Trabalhos anteriores já mencionaram que os níveis de PCR encontrados por um laboratório não podem ser comparados com os de outro [10]. Esta informação, aliada ao fato de se tratarem de duas técnicas diferentes, explica por que os valores de PCR observados entre as duas técnicas foram diferentes $(\mathrm{p}<0,05)$. Assim, tais valores de referência (Tabela 1) devem ser considerados quando esta técnica for empregada clinicamente. Pode-se afirmar que a técnica é precisa, amparando-se nos mesmos resultados observados entre os grupos, por ambas as técnicas (valores

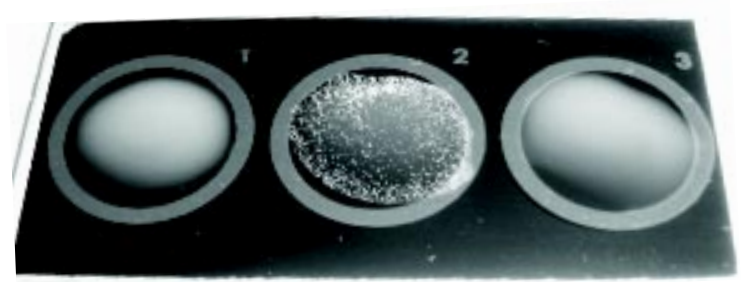

Figura 3. Teste de aglutinação em látex. Amostra 2: positiva (níveis de PCR > 6mg/L); Amostras 1 e 3: negativas (níveis de $\mathrm{PCR}<6 \mathrm{mg} / \mathrm{L}$ ). 
mais baixos em animais obesos do que em controles), devido a ambas as técnicas terem sido empregadas no soro dos mesmos animais e pela correlação positiva altamente significativa entre as duas técnicas.

$\mathrm{O}$ fato de os animais obesos apresentarem valores mais baixos do que os controles já foi discutido em trabalhos anteriores [14], sendo explicado pelo efeito do colesterol e dos triglicerídeos sobre a PCR e não é o objetivo do presente experimento. Os níveis de PCR de todos os animais determinados através de ELISA permaneceram dentro dos valores de referência para o teste. Assim, pode ser extrapolado que os valores encontrados na prova de aglutinação em látex também se encontram dentro do normal para a espécie, para o tipo de técnica.

Os problemas encontrados durante o emprego da técnica considerada gold standard durante o presente experimento consistiram em dificuldades econômicas, necessidade de importação do produto, demora na execução e inexistência de um equipamento leitor no laboratório em que o experimento foi realizado, havendo a necessidade de se recorrer a um laboratório localizado a cerca de $5 \mathrm{~km}$ de distância para a realização das leituras. Por sua vez, o kit de aglutinação em látex pôde ser encontrado comercialmente na própria cidade em que o experimento foi realizado, o custo com material de consumo por amostra na utilização deste teste foi aproximadamente 76,8\% menor em relação à ELISA e à técnica pôde ser empregada no ambulatório, sem a necessidade de se adquirir equipamentos.

\section{CONCLUSÃO}

Conclui-se que o kit humano de aglutinação em látex pode ser utilizado clinicamente para a determinação semiquantitativa dos níveis séricos de PCR canina. Porém, a sua interpretação deve ser embasada em valores de referência obtidos através da mesma técnica.

Agradecimentos. Os autores agradecem aos órgãos financiadores: CNPq, Waltham, Helica Biosystems e ao imunologista, Dr. Wondu Wolde-Mariam, pela doação de kits ELISA caninos, para determinação dos níveis de PCR.

\section{NOTAS INFORMATIVAS}

${ }^{1}$ Helica Biosystems, Califórnia, USA.

${ }^{2}$ In Vitro Diagnóstica, Minas Gerais, Brasil.

${ }^{3}$ Anthos, Cambridge, UK.

${ }^{4}$ SAS Institute, North Carolina, EUA.

\section{REFERÊNCIAS}

1 Bharadwaj D., Stein M.-P., Volzer M., Mold C. \& Du Clos T.W. 1999. The major receptor for C-reactive protein on leukocytes is fc \{gamma\} receptor II. Journal of Experimental Medicine. 190: 585-590.

2 Conner J. G., Eckersall P.D., Ferguson J. \& Douglas T. A. 1988. Acute phase response in the dog following surgical trauma. Research in Veterinary Science. 45: 107-110.

3 Kjelgaard-Hansen M., Kristensen A.T. \& Justen A.L. 2003. Evaluation of a commercially available enzyme-linked immunosorbent assay (elisa) for the determination of C-reactive protein in canine serum. Journal of Veterinary Medicine A. 50: 164-168.

4 Kuribayashi T., Shimada T., Matsumoto M., Kawato K., Honjyo T., Fukuyama M., Yamamoto Y. \& Yamamoto S. 2003. Determination of serum c-reactive protein (crp) in healthy beagle dogs of various ages and pregnant beagle dogs. Experimental Animals. 52: 387-390.

5 Laflamme D.P. 2005. Nutrition for aging cats and dogs and the importance of body condition. Veterinary Clinics of North America: Small Animal Practice. 35: 713-742.

6 Mawby D.I., Bartges J.W., d'Avignon A., Laflamme D.P., Moyers T.D. \& Cottrell T. 2004. Comparison of various methods for estimating body fat in dogs. Journal of the American Animal Hospital Association. 40: 109-114.

7 McGrotty Y.L., Knottenbelt C.M., Ramsey I.K., Reid S.W.J. \& Eckersall P.D. 2004. Evaluation of a rapid assay for canine C-reactive protein. Veterinary Record. 154: 175-176.

8 Murata H., Shimada N. \& Yoshioka M. 2004. Current research on acute phase proteins in veterinary diagnosis: An overview. The Veterinary Journal. 168: 28-40.

9 Nakamura M., Takahashi M., Ohno K., Koshino A., Nakashima K., Setoguchi A., Fujino Y. \& Tsujimoto H. 2008. Creactive protein concentration in dogs with various diseases. The Journal of Veterinary Medical Science. 70: 127-131.

10 Oyamada H.N.O. \& Uesugi S. 1992. Quantitative assays for C-reactive protein: a review. Rinsho Byori. The Japanese Journal of Clinical Pathology. 40: 9-15. 
11 Parra M., Tuomola M., Cabezas-Herrera J. \& Cerón J. 2006. Analytical and clinical validation of a time-resolved immunofluorometric assay (TR-IFMA) for canine c-reactive protein in serum. Veterinary Research Communications. 30: 113-126.

12 Tagata K., Yokoyama S., Ginbo T., Honda M., Okimura T., Odakura M., Nomura M. \& Yamamoto S. 1996. Quantitative capillary reversed passive latex agglutination test for C-reactive protein (crp) in the dog. Veterinary Research Communications. 20: 21-30.

13 Vecina J.F., Patrício R.F. \& Ciarlini P.C. 2006. Importância do fibrinogênio plasmático na identificação de processos inflamatórios de cães. Ciência Veterinária nos Trópicos. 9: 3135.

14 Veiga A.P.M., Price C.A., de Oliveira S.T., dos Santos A.P., Campos R., Barbosa P.R. \& Gonzalez F.H.D. 2008. Association of canine obesity with reduced serum levels of c-reactive protein. Journal of Veterinary Diagnostical Investigation. 20: 224-228.

15 Yamamoto S. S.T., Miyaji H, Santsuka H., Fujise H., Mukawa K., Furukawa E., Nagae T., \& Naiki M. 1994. Determination of C-reactive protein in serum and plasma from healthy dogs and dogs with pneumonia by ELISA and slide reversed passive latex agglutination test.Veterinary Quarterly. 16:74-7. 